\title{
SISTEM APLIKASI PENGAMBILAN NOMOR ANTRIAN BERBASIS ANDROID PADA RUMAH SAKIT IMANUEL BANDAR LAMPUNG
}

\author{
Sukatmi ${ }^{1}$, Naomi Ristani ${ }^{2}$ \\ ${ }^{1}$ Dosen AMIK Dian Cipta Cendikia Bandar Lampung \\ ${ }^{1}$ E-mail : sukatmi@dcc.ac.id \\ ${ }^{2}$ E-mail : naomibekscr7@gmail.com
}

\begin{abstract}
ABSTRAK
Selama ini pasien yang akan memeriksakan kesehatan ke dokter di rumah sakit harus terlebih dahulu mengantri untuk mengambil nomor antrian pendaftaran. Terjadinya antrian dikarenakan sistem layanan di rumah sakit tersebut masih dilakukan dengan cara manual yaitu pasien harus mengantri berdasarkan urutan bangku saat mereka menunggu, lalu satu persatu akan dilayani untuk mendapatkan nomor antrian. Proses menunggu yang terlalu lama dan terbatasnya sumber daya yang ada sehingga sering terjadi antrian panjang. Permasalahan diatas juga dialami di Rumah Sakit Imanuel. Oleh karena itu, diperlukan suatu sistem untuk menanggulangi permasalahan antrian tersebut.

Sistem Aplikasi Pengambilan Nomor Antrian Berbasis Android ini dibuat menggunakan aplikasi Dreamweaver CS8 dengan database MySQL. Sistem ini dirancang untuk pengambilan nomor antrian melalui android. Metode yang digunakan menggunakan Metode Extreme Programming. Data-data yang digunakan dalam pembuatan sistem ini adalah data-data yang berhubungan dengan proses pengambilan nomor antrian.

Berdasarkan hasil penelitian yang telah diimplementasikan kedalam program Sistem Aplikasi Pengambilan Nomor Antrian Berbasis Android ternyata dapat memberikan kemudahan dalam proses pengambilan nomor antrian yang dapat dilakukan melalui android dan output yang didapat berupa notifikasi nomor antrian.
\end{abstract}

\section{Kata Kunci : Aplikasi Berbasis Android, Dreamweaver CS8, MySql}

During this patient who will check the health to the doctor in the hospital must first queue to take the registration queue number. The queue occurred because the service system in the hospital is still done by manual, the patient must queue based on the order of the bench while they wait, then one by one will be served to get the queue number. The process of waiting is too long and limited resources so there is often a long queue. The above problems are also experienced in Imanuel Hospital. Therefore, a system is needed to overcome these queuing problems.

Application System Taking Android Based Queue Number is made using Dreamweaver CS8 application with MySQL database. This system is designed for queue number retrieval via android. The method used using Extreme Programming Method. The data used in making this system is the data associated with the process of queue number retrieval.

Based on the results of research that has been implemented into the Application System Application Queue Based Android based queue was able to provide convenience in the process of queue number retrieval that can be done through android and output obtained in the form of notification queue number.

Keywords: Android Based Application, Dreamweaver CS8, MySql 


\section{PENDAHULUAN}

Dalam setiap aktivitas, tidak jarang ditemukan masalah garis tunggu (waiting lines) atau masalah antrian. Antrian timbul disebabkan oleh kebutuhan akan layanan melebihi kemampuan (kapasitas) pelayanan atau fasilitas pelayanan, sehingga pengguna fasilitas yang tidak bisa segera mendapat layanan. Contoh salah satu layanan publik yang sering mengalami masalah antrian adalah pada Rumah Sakit Imanuel.

Rumah Sakit Imanuel adalah salah satu rumah sakit swasta di Lampung yang beralamatkan di Jl. Soekarno Hatta, Way Halim, Bandar Lampung. Dengan mengusung motto "Mengasihi Semua, Melayani Semua", Rumah Sakit Imanuel selalu berusaha untuk menjadi layanan publik yang dapat memberikan pelayanan kepada seluruh lapisan masyarakat. Sebagai salah satu rumah sakit terbesar di Lampung, Rumah Sakit Imanuel selalu ramai didatangi para pasien yang ingin mendapatkan pengobatan terbaik.

Namun dibalik pelayanan terbaik yang diberikan Rumah Sakit Imanuel, masih terdapat permasalahanpermasalahan yang harus segera ditangani oleh pihak manajemen Rumah Sakit Imanuel. Salah satu permasalahan yang harus segera ditangani adalah masalah pengambilan antrian. Terjadinya antrian dikarenakan sistem layanan di rumah sakit tersebut masih dilakukan dengan cara manual yaitu pasien harus mengantri berdasarkan urutan bangku saat mereka menunggu, lalu satu persatu akan dilayani untuk mendapatkan nomor antrian. Proses menunggu yang terlalu lama dan terbatasnya sumber daya yang ada sehingga sering terjadi penumpukkan antrian.

Untuk pasien BPJS, paling sering terjadi penumpukan antrian. Mereka bahkan sudah menunggu sejak loket pengambilan antrian belum dibuka oleh petugas. Mereka beralasan agar bisa mendapatkan nomor antrian. Hal itu dikarenakan Rumah Sakit Imanuel membatasi jumlah pasien peserta BPJS pada setiap dokter. Sehingga sistem seperti ini masih kurang efektif untuk diterapkan pada rumah sakit tersebut. Oleh karena itu, diperlukan suatu sistem untuk menanggulangi permasalahan antrian tersebut.

\section{METODE PENELITIAN}

Alur penelitian Sistem Aplikasi Pengambilan Nomor Antrian Berbasis Android Pada Rumah Sakit Imanuel Bandar Lampung dapat dilihat pada gambar 1.

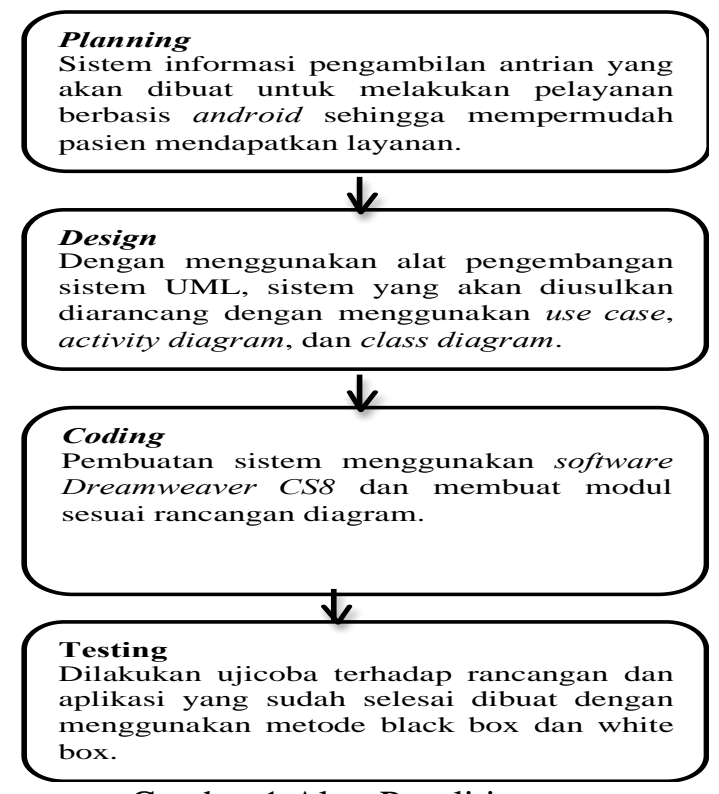

Gambar 1 Alur Penelitian 


\subsection{Landasan Teori}

\subsubsection{Aplikasi}

Aplikasi berasal dari kata application yang artinya penerapan, lamaran, penggunaan. Secara istilah aplikasi adalah program siap pakai yang dibuat untuk melaksanakan suatu fungsi bagi pengguna atau aplikasi yang lain dan dapat digunakan oleh sasaran yang dituju.

Menurut Jogiyanto (1999:12), aplikasi merupakan penggunaan dalam suatu komputer, instruksi (instruction) atau pernyataan (statement) yang disusun sedemikian rupa sehingga komputer dapat memproses input menjadi output.

\subsubsection{Antrian}

Pengertian antrian menurut Ma'arif dan Tanjung (2003:119) adalah sebagai berikut: "Situasi barisan tunggu dimana sejumlah kesatuan fisik (pendatang) sedang berusaha untuk menerima pelayanan dari fasilitas terbatas (pemberi pelayanan), sehingga pendatang harus menunggu beberapa waktu dalam barisan agar dilayani".

Sedangkan menurut Heizer dan Render (2006:658) dalam bukunya Operation Management yang diterjemahkan oleh Setyoningsih dan Almahdya adalah sebagai berikut: "Teori antrian adalah ilmu pengetahuan tentang antrian dan antrian merupakan orang-orang atau barang dalam barisan yang sedang menunggu untuk dilayani”.

\subsubsection{Android}

Menurut Hermawan (2011:1), Android merupakan OS (Operating System) Mobile yang tumbuh ditengah OS lainnya yang berkembang dewasa ini. OS lainnya seperti Windows Mobile, i-Phone OS, Symbian, dan masih banyak lagi. Akan tetapi, OS yang ada ini berjalan dengan memperioritaskan aplikasi inti yang dibangun sendiri tanpa melihat potensi yang cukup besar dari aplikasi pihak ketiga. Oleh karena itu, adanya keterbatasan dari aplikasi pihak ketiga untuk mendapatkan data asli ponsel, berkomunikasi antar proses serta keterbatasan distribusi aplikasi pihak ketiga untuk platform mereka.

\subsubsection{Dreamweaver CS8}

Dreamweaver merupakan software utama yang digunakan oleh Web Designer dan Web Programmer dalam mengembangkan suatu situs web. Hal ini disebabkan oleh ruang kerja, fasilitas, dan kemampuan Dreamweaver yang mampu meningkatkan produktivitas dan efektivitas, baik dalam desain maupun membangun suatu situs web.dalam perkembangannya, Adobe Dreamweaver telah mencapai versinya yang terbaru atau lebih dikenal Adobe Dreamweaver CS8. Fitur-fitur yang dimiliki semakin lengkap dan handal, untuk membuat pengguna Dreamweaver CS8 semakin dapat berkreasi dan berinovasi dengan bebas dalam mendesain web.

Fitur baru yang semakin handal untuk versi terbaru ini dimunculkan, diantaranya adalah Integrated CMS Support, CSS Inspetion, PHP Custom Class Code Hinting, dan Site-Specific Code Hinting. Semua fitur baru tersebut semakin memantapkan pengguna Adobe Dreamweaver CS8 untuk semakin mengeksplorasi dan mengeksploitasi ide kreasi pengolahan website.

\subsubsection{PHP}

Menurut Saputra (2012:5), PHP merupakan bahasa Server Side Scripting, dimana PHP selalu membutuhkan web server dalam menjalankan aksinya. Secara prinsip, server akan bekerja apabila ada permintaan dari client, yaitu kode-kode PHP. Client tersebut akan dikirimkan ke server, kemudian server akan mengembalikan pada halaman sesuai instruksi yang diminta. Berikut adalah uraian per poinnya:

1. Server membaca perintah dari client/browser.

2. Kemudian dilanjutkan untuk mencari halaman/page pada server.

3. Server melakukan instruksi yang diberikan oleh PHP untuk melakukan modifikasi pada halaman/page. 
4. Selanjutnya hasil modifikasi tersebut akan dikembalikan kepada client/browser.

\subsubsection{MySQL}

MySQL merupakan DBMS yang multithread dan multiuser yang bersifat gratis dibawah lisensi GNU General Public Licence (GPL). Tidak seperti Apache yang merupakan software yang dikembangkan oleh komunitas umum, dan hak cipta untuk kode sumber dimiliki oleh penulisnya masing-masing. Seperti yang telah disebutkan sebelumnya, MySQL bersifat gratis atau open source sehingga kita bisa menggunakannya secara gratis. Adapun kelebihan-kelebihan dari MySQL yaitu sebagai berikut:

1. Source MySQL dapat diperoleh dengan mudah dan gratis.

2. Sintaksnya lebih mudah dipahami dan tidak rumit.

3. Pengaksesan database dapat dilakukan dengan mudah.

4. MySQL merupakan program yang multithreaded, sehingga dapat dipasang pada server yang memiliki multiCPU.

5. Didukung program-program umum seperti C, C++, Java, Perl, PHP, Python, dsb.
6. Bekerja pada berbagai platform (tersedia berbagai versi untuk berbagai sistem operasi).

7. Memiliki jenis kolom yang cukup banyak sehingga memudahkan konfigurasi sistem database.

8. Memiliki sistem sekuriti yang cukup baik dengan verifikasi host

\section{HASIL DAN PEMBAHASAN}

\subsection{Perancangan Sistem}

\subsubsection{Planning}

Pada tahap ini dibuat perencanaan penelitian mulai dari melakukan observasi langsung ke tempat penelitian, mengumpulkan data-data, menentukan perangkat keras (hardware) dan perangkat lunak (software) yang akan dibutuhkan untuk pembuatan program aplikasi.

\subsubsection{Design}

Pada tahap ini dibuat rancangan sistem sebagai berikut.

\subsubsection{Alur Sistem yang Diusulkan}

Alur sistem yang diusulkan dibuat dalam bentuk usecase diagram seperti pada gambar 2.

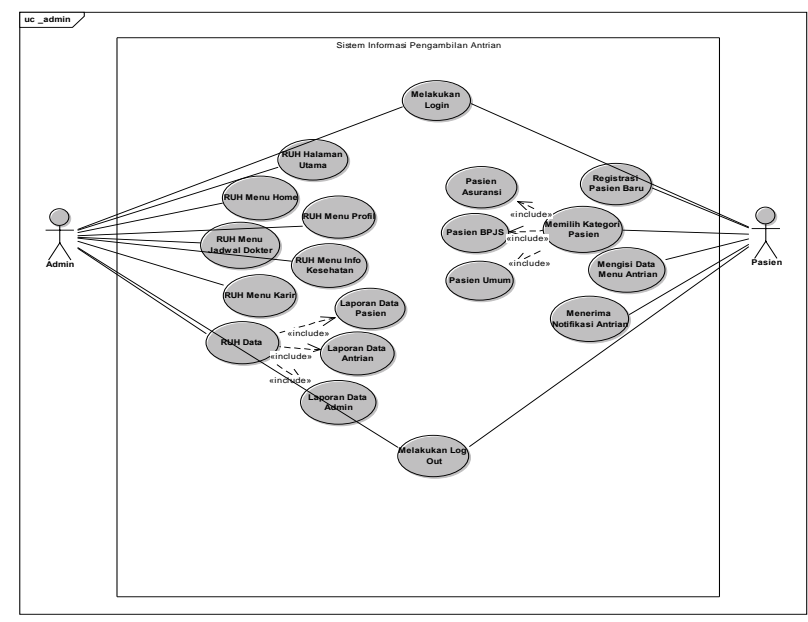

Gambar 2. Use Case Diagram Admin dan Pasien Pada Sistem Informasi Pengambilan Antrian Berbasis Android 


\subsubsection{Rancangan Basis Data}

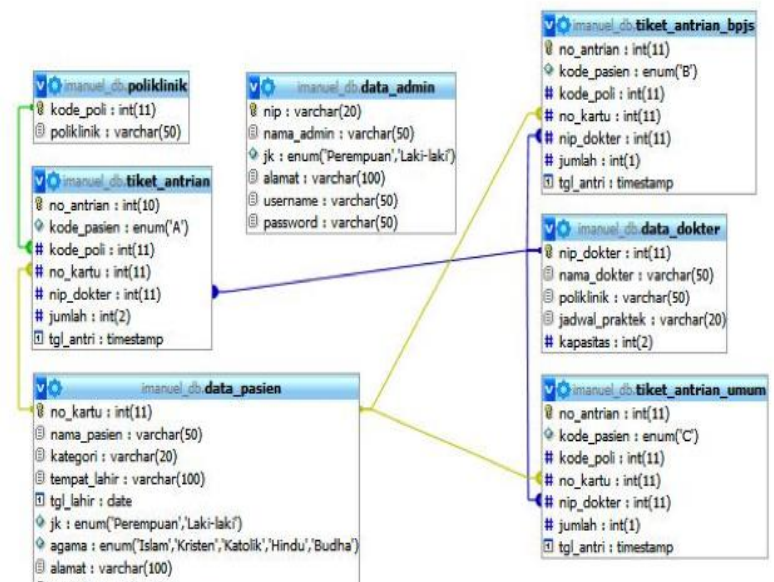

Gambar 3. Class Diagram Sistem Aplikasi Pengambilan Nomor Antrian

\subsubsection{Activity Diagram}

Activity Diagram Jadual Dokter

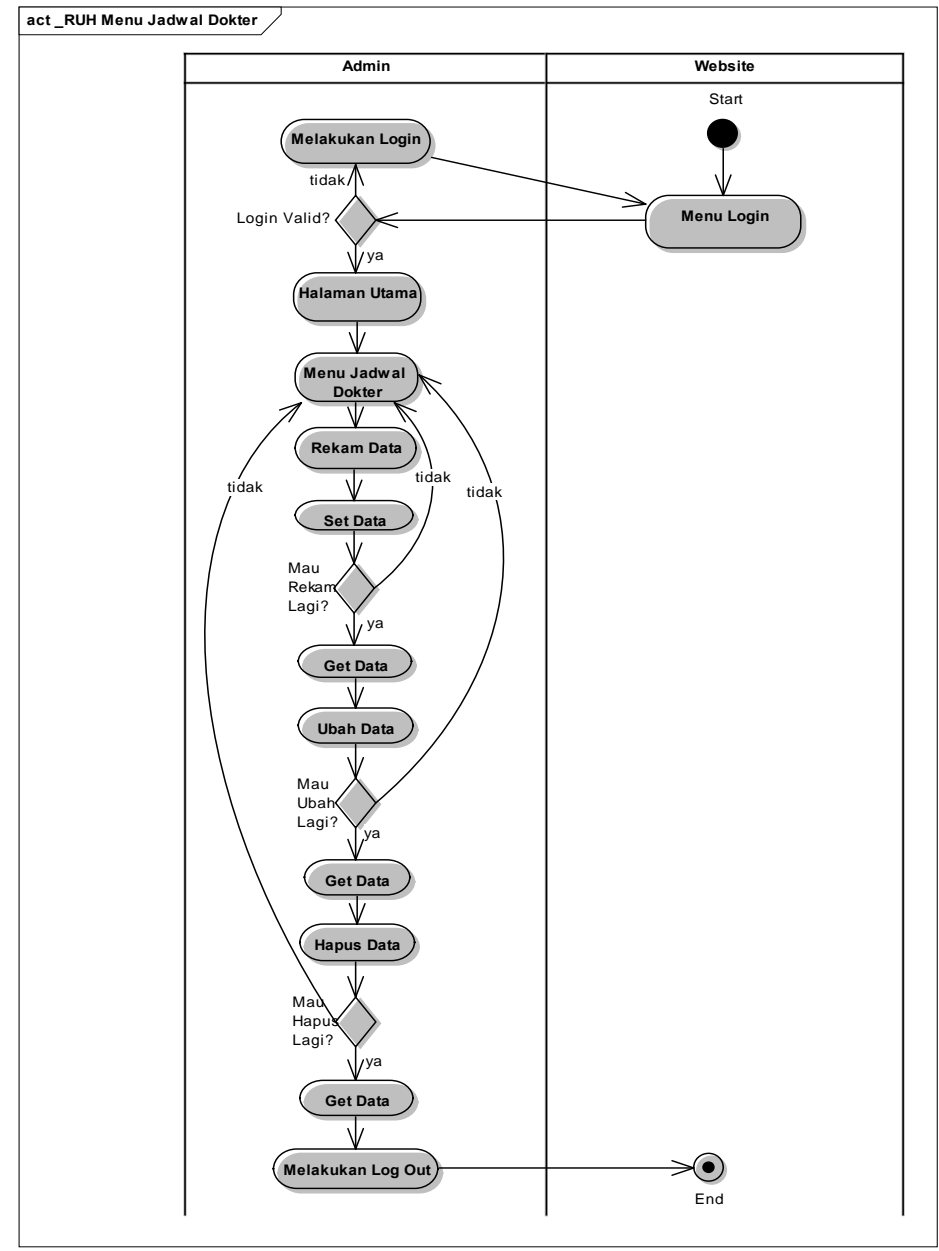

Gambar 4. Activity Diagram RUH Menu Jadwal Dokter oleh Admin 


\section{Activity Diagram Pengambilan Nomor Antrian}

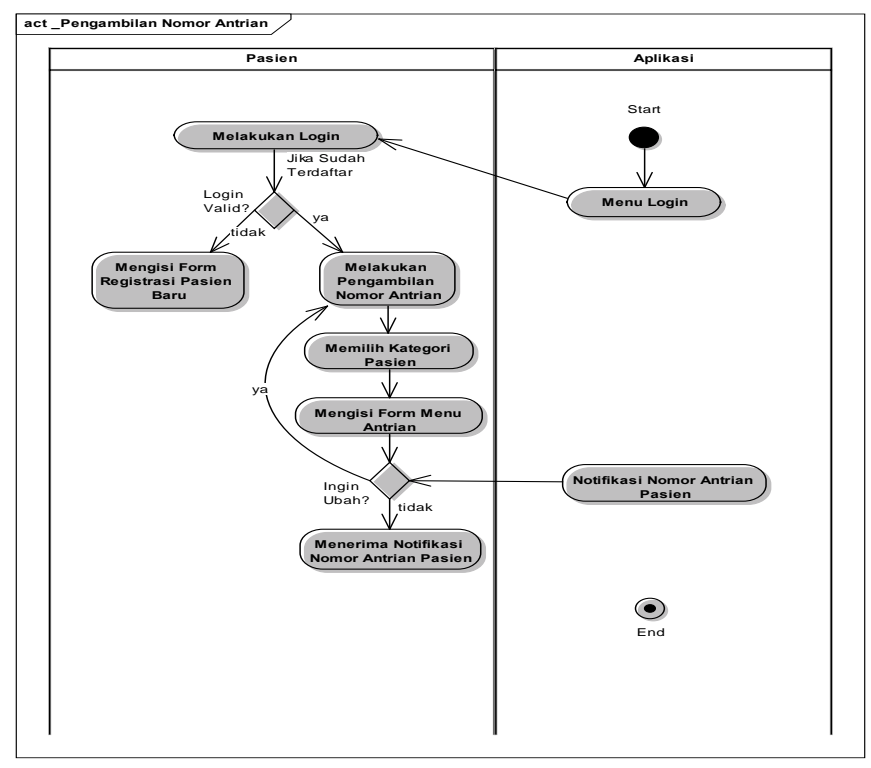

Gambar 5. Activity Diagram Pasien Melakukan Pengambilan Nomor Antrian

\section{Activity Diagram Regristrasi Pasien Baru}

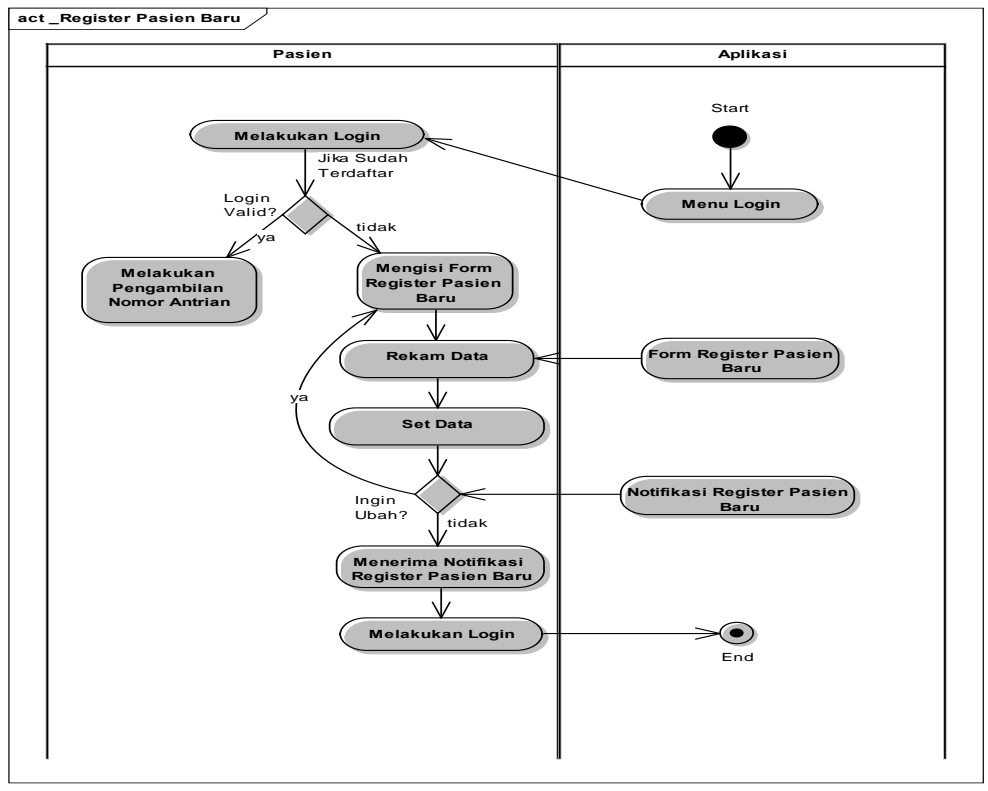

Gambar 6. Activity Diagram Registrasi Pasien Baru

\subsection{Hasil Program}

\subsubsection{Form Login Pasien}

Pada form login, pasien diminta memasukkan nama pasien dan nomor kartu kemudian klik login untuk masuk ke menu antrian. Pasien dapat melakukan login apabila sudah terdaftar sebagai pasien dan memiliki kartu berobat Rumah Sakit Imanuel. Jika inputan nama pasien dan nomor kartu benar maka akan masuk ke menu antrian dengan menu-menu yang ditampilkan. Namun jika inputan nama pasien dan nomor kartu salah maka ada pesan konfirmasi kesalahan dan pasien diminta memasukkan kembali data login dengan benar. Apabila pasien belum terdaftar dan belum memiliki kartu berobat maka harus melakukan pendaftaran pasien 
terlebih dahulu dengan mengklik kata disini untuk menampilkan form input data pasien.

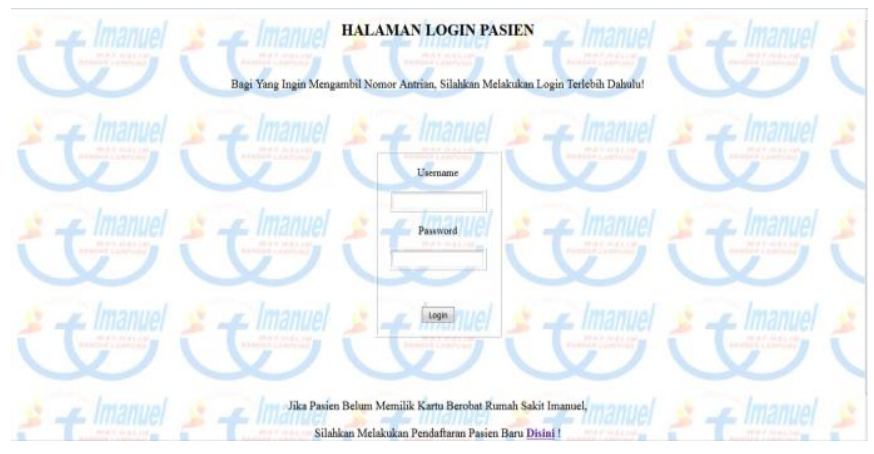

Gambar 7. Tampilan Form Login Pasien Pada Aplikasi

\subsubsection{Menu Antrian}

Menu antrian adalah menu yang disediakan untuk pasien yang ingin melakukan pengambilan nomor antrian di Rumah Sakit Imanuel. Menu antrian ini terdiri dari beberapa form inputan yaitu: Form Kategori Antrian, Form Menu Antrian.

\section{Form Kategori Antrian}

Form kategori antrian ini dimaksudkan untuk pasien menginput kategori pasien tersebut. Form ini berupa pilihan kategori antrian yang terdiri dari Asuransi, BPJS, dan Umum.

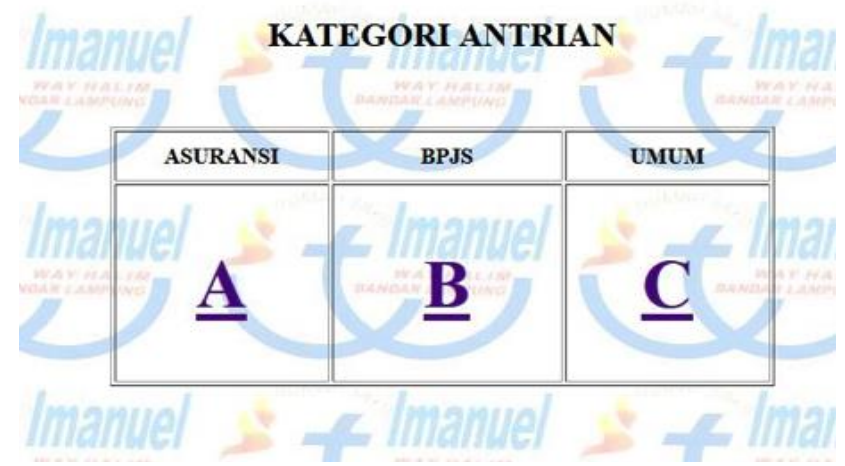

Gambar 8. Tampilan Form Kategori Antrian Pada Aplikasi

\section{Form Input Antrian}

Form input antrian ini dimaksudkan untuk pasien menginput data-data yang diperlukan umtuk mengambil nomor antrian. Seperti: No. Kartu Pasien, Kode Dokter, Jumlah Antrian.

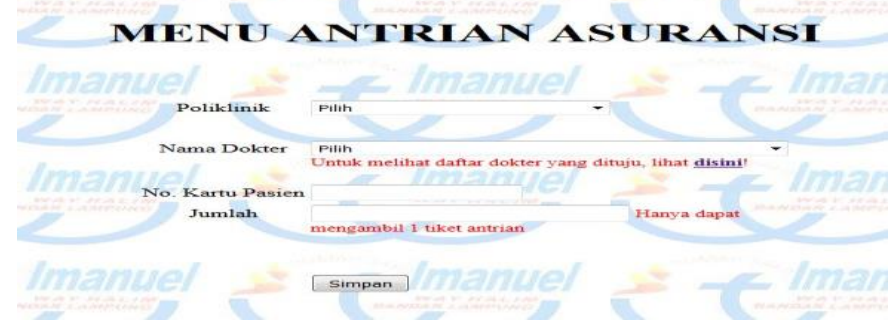

Gambar 8. Salah Satu Tampilan Form Input Antrian Pada Aplikasi 


\section{Tampilan Notifikasi Nomor Antrian}

Pada bagian ini menampilkan tampilan notifikasi nomor antrian pasien. Output notifikasi ini diperoleh setelah pasien melakukan transaksi penginputan data antrian yang terdapat pada aplikasi antrian. Isi dari notifikasi nomor antrian ini berupa Nomor Antrian Pasien, Poliklinik yang dituju, Nama Dokter, Jadwal Checkup Pasien, dan Waktu pasien melakukan transaksi antrian.

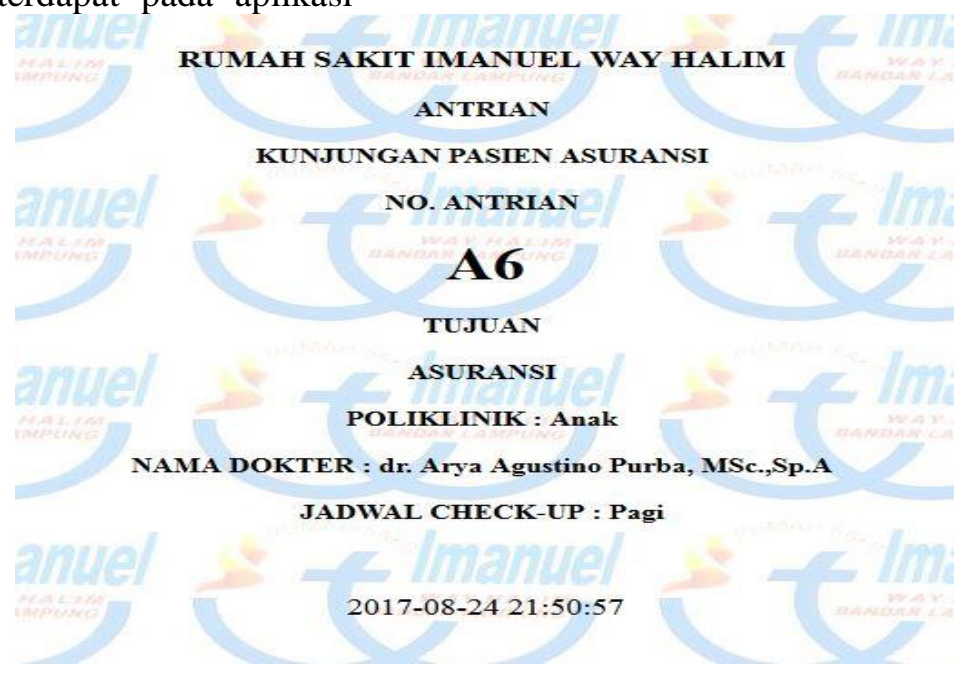

Gambar 9. Salah Satu Tampilan Output Notifikasi Nomor Antrian Pasien

\section{Laporan Data Antrian}

Laporan data antrian adalah laporan data antrian yang berisikan data-data antrian pasien yang terjadi di Rumah Sakit Imanuel. Untuk membuat laporan ini admin dapat mencetaknya dengan terlebih dahulu masuk ke Main Menu Admin, lalu pilih Menu Master Data Antrian, lalu pilih kategori antrian, setelah tampil kemudian klik pilihan print.

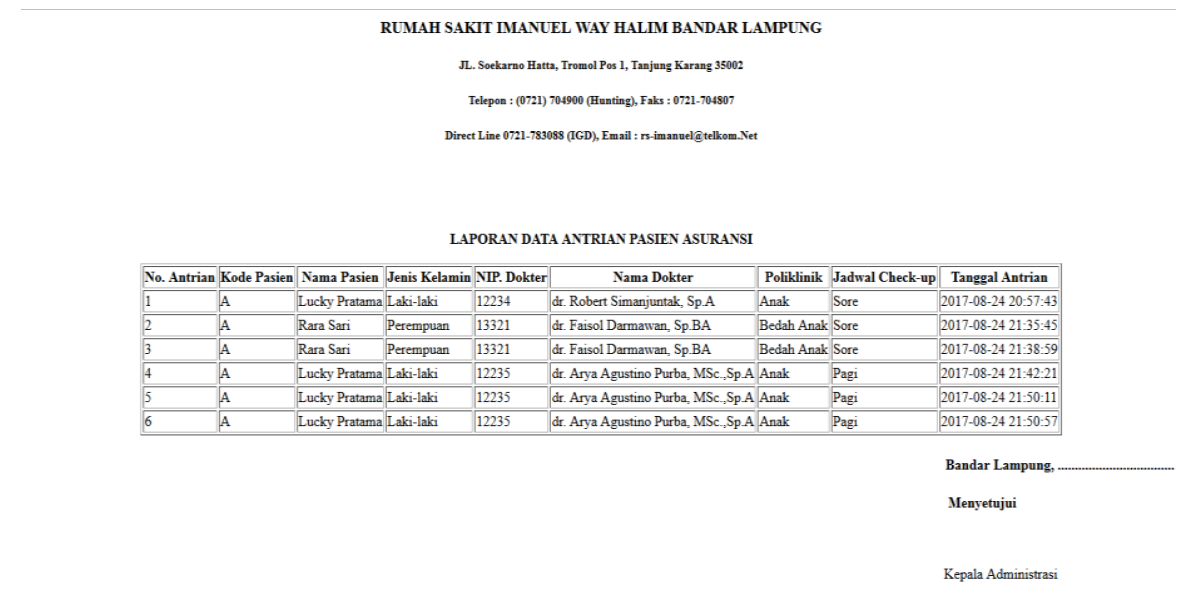

Gambar 10. Salah Satu Tampilan Laporan Data Antrian Pasien Di Menu Admin

\subsection{Pembahasan Hasil program}

Aplikasi Pengambilan Nomor

Antrian berbasis Android ini dirancang dengan menggunakan bahasa pemrograman PHP, aplikasi Dreamweaver CS8, dan database MySQL. Sistem ini dibuat agar mempermudah pasien dalam melakukan proses pengambilan nomor antrian. Sistem ini dapat dioperasikan dimana saja sehingga menghemat waktu pasien tersebut. 
Admin adalah bagian yang bertugas untuk mengurus data-data di Rumah Sakit Imanuel. Salah satunya adalah data-data yang menyangkut dengan proses antrian. Seperti data pasien dan data antrian yang ada di Rumah Sakit Imanuel. Data-data tersebut akan disimpan pada sistem database yang dikelola oleh admin. Setelah itu admin akan membuat laporan yang nantinya akan diperlukan dan sudah ditandatangani oleh Kepala Administrasi.

Keunggulan Sistem

1. Mudah dalam mengoperasikannya.

2. Dapat dilakukan dimana saja sehingga menghemat waktu pasien.

3. Berbasis Android

Kelemahan Sistem

1. Kecepatan dalam proses pengambilan nomor antrian tergantung dari jaringan koneksi internet yang digunakan oleh pasien.

2. Dibutuhkan sistem keamanan yang tinggi karena sistem terpusat dan dapat diakses oleh banyak orang.

\section{SARAN}

1. Aplikasi Pengambilan Nomor Antrian Berbasis Android ini diharapkan bisa dijadikan referensi bagi pihak RS. Imanuel untuk membuat aplikasi serupa agar mempermudah pasien mengambil nomor antrian.

2. Aplikasi Pengambilan Nomor Antrian Berbasis Android Pada Rumah Sakit Imanuel ini hendaknya dapat dikembangkan guna kebutuhan kinerja dimasa yang akan datang.

\section{Daftar Pustaka}

Heizer dan Render. 2006. Operations Management. New Jersey: Prentice Hall

HM, Jogiyanto. 1999. Analisis dan Desain Sistem Infromasi: Pendekatan Terstruktur Teori dan Praktek Aplikasi Bisnis. Yogyakarta: Andi Offset

Ibisa. 2010. Evaluasi Paket Sistem Aplikasi Web. Yogyakarta: Andi Offset
Maarif, Syamsul dan Hendri

Tanjung. 2003. Manajemen

Operasi. Jakarta: Grasindo

Pressman, RS. 2012. Rekayasa

Perangkat Lunak: Pendekatan

Praktisi. Yogyakarta: Andi

Publisher

Santoso, Harip. 2000. Membangun Aplikasi Web. Jakarta: PT. Elex Media Komputindo

Saputra, Agus. 2012. Web Tips PHP, HTML5 dan CSS3. Jakarta: Jasakom

Subhan, Mohammad. 2012. Analisa Perancangan Sistem. Jakarta: Lentera Ilmu Cendekia

Supriyanto. 2005. Perancangan Aplikasi. Surabaya: Widyastana

Tantra, Rudy. 2012. Manajemen Proyek Sistem Informasi. Yogyakarta: Andi Offset

Versianita, Nuning dkk. 2012. Perancangan Sistem Antrian Pelayanan Rawat Jalan pada Rumah Sakit Islam Ibnu Sina Yarsi Sumber Padangpanjang menggunakan PHP dan MySQL, 09101152630044_Nuning

Versianita_Teknik Informatika, dalam

https://www.scribd.com/doc/201640

956/09101152630044-Nuning-

Versianita-Teknik-Informatika

diakses 27 November 2011

Wiraputra, I Made Agus. 2011. Rancang Bangun Sistem Informasi Pelayanan Pasien Rawat Jalan Tuberkulosis Berbasis SMS Gateway Pada RSUD Sanjiwani Gianyar, STIKOM Surabaya-Undergraduate-4-22318, dalam digilib.stikom.edu, diakses 10 Januari 2011

WP, Hengky. 2012. Aplikasi Inventory Berbasis Access 2003. Jakarta: PT. Elex Media Komputindo

Yakub. 2012. Pengantar Sistem Informasi. Yogyakarta: Graha Ilmu 